\title{
Review of Heterotopic Thyroid Autotransplantation
}

\author{
Mahmoud Sakr · Ahmed Mahmoud \\ Department of Surgery, Faculty of Medicine, Alexandria University, Alexandria, Egypt
}

Total thyroidectomy is increasingly accepted for the management of bilateral benign thyroid disorders. Postoperatively, patients require lifelong levothyroxine replacement therapy to avoid postoperative hypothyroidism, which besides the burden of compliance, has been proven to be associated with several long-term side effects. Heterotopic thyroid autotransplantation was proposed several decades ago to avoid the need for life-long postoperative replacement therapy with maintaining the autoregulatory mechanism of thyroxin production inside the body according to its needs. Available data regarding this topic in literature is relatively poor. Before applying thyroid autotransplantation on humans, several studies have been done on animals, where the autologous transplantations were found to be successful in almost all the cases, proved by follow up postoperative 8-week measurements of thyroid hormones and histopathological examination of the removed autografts. Regarding the clinical application, few trials have been done using cryopreserved in vivo, in vitro or immediately autotransplanted thyroid autografts. Satisfactory results were obtained, however, the number of these studies and the number of patients per each study was very low. Besides the study methodologies were not so consistent.

Keywords. Thyroid; Transplantation, Autologous; Transplantation, Heterotopic; Thyroidectomy; Review

\section{INTRODUCTION}

Total thyroidectomy (TT) is now the mainstay procedure for management of patients with bilateral benign thyroid disorders. Many authors have reported that TT is now performed safely, and that low complication rates can be achieved with a meticulous surgical technique [1,2]. Although surgery is a good choice to avoid habitual consumption of medications, but patients still require life-long levothyroxine (L-T4) replacement therapy which has been reported to be associated with coronary heart disorders and dysfunction of lipid metabolism [3,4]. Apparently, postoperative control of hypothyroidism after TT by L-T4 replacement therapy seems easy, but for the patient, a daily dose of L-T4 and regular follow-up visits to the hospital may become somewhat a burden, and may interfere with reaching a euthyroid status using replacement therapy due to noncompliance of

\footnotetext{
- Received December 16, 2016

Revised March 16, 2017

Accepted April 19, 2017

- Corresponding author: Mahmoud Sakr

Department of Surgery, Faculty of Medicine,Alexandria University,

Champillion St,Azarita,Alexandria 21500, Egypt

Tel: +20-10-07834993, Fax: +20-3-5899420

E-mail: mah_sakr@yahoo.com
}

the patient [5]. Another problem that may interfere with reaching a euthyroid status using replacement therapy is malabsorption of the medication due to any gastrointestinal disorder [6]. Autotransplantation of benign thyroid tissue after TT helps avoid life-time thyroid hormonal replacement therapy. Another advantage of heterotopic thyroid autotransplantation is maintaining the autoregulatory mechanism of thyroxin production inside the body according to its needs [7]. Heterotopic thyroid autotransplantation was proposed to avoid reoperation at the site of previous neck surgery in cases of recurrent goiters or recurrent hyperthyroidism. In this article, we are aiming at reviewing the history of thyroid transplantation regarding it experimental trials and clinical applications.

\section{LITERATURE REVIEW}

A meticulous search in the literature was done for English articles reviewing thyroid autotransplantation published till 2015. The databases searched included Springer, PubMed, ScienceDirect, and the Cochrane Central Register of Controlled Trials. Other important references were obtained from the bibliographies of selected recent articles.

Copyright @ 2017 by Korean Society of Otorhinolaryngology-Head and Neck Surgery.

This is an open-access article distributed under the terms of the Creative Commons Attribution Non-Commercial License (http://creativecommons.org/licenses/by-nc/4.0)

which permits unrestricted non-commercial use, distribution, and reproduction in any medium, provided the original work is properly cited. 


\section{FAILINGS OF LEVOTHYROXINE REPLACEMENTTHERAPY AFTERTOTAL THYROIDECTOMY}

All patients afterTT or should receive L-T4 replacement therapy for life in order to avoid hypothyroidism. Some patients who underwent subtotal thyroidectomy (STT) and even hemithyroidectomy also require such replacement therapy. Postoperative L-T4 has been commonly prescribed for physiologic replacement of hypothyroidism over the many last years and there is no doubt about its efficacy and relative safety. It has many advantages, which include a long half-life, once-daily administration and no harm resulting from the occasional missing of a tablet. The low cost is another advantage [8,9]. However, several failings have been reported with life-long administration of L-T4 which must be taken into consideration.

Poor compliance of the patients is of utmost importance, a study was performed in Brazil by Bagattoli et al. [10] in 2000, involving patients with decompensated hypothyroidism, of which more than $80 \%$ did not follow the medical instructions due to prescription misunderstanding or forgetfulness.

Several factors have contributed to the failure of some generic L-T4 products. The most critical factors are tablet potency, limited bioavailability of the generic preparation caused by poor or reduced absorption of thyroxine (T4) from the gut and the shelf life of the tablet. It has been reported that L-T4 tablets lose T4 at a rate of $5 \%$ per year [11].

Although international organizations continuously recommend L-T4 monotherapy for treatment of hypothyroid patients, polymorphism of $\mathrm{D} 2$ gene should be considered in such patients who usually complain of fatigue in spite of proper L-T4 dosage and low normal serum thyroid stimulating hormone (TSH) levels achieved. An important clue to this D2 gene polymorphism could be a higher than normal free thyroxine (FT4) and free triiodothyronine (FT3) ratio [12]. In such patients, T3 with L-T4 combined therapy is advised.

Postmenopausal women on life-long L-T4 replacement therapy have a greater hazard of bone loss [13]. The meta-analysis by Faber and Galloe [14] in 1994, found that the bone mineral density in postmenopausal women on L-T4 suppressive treatment

\section{H I G H L I G G H T S}

- Thyroid autotransplantation was proposed to avoid life-long levothyroxine replacement.

- Several failings have been reported with life-long administration of levothyroxine.

- Experimental studies showed that autologous transplantation was successful in all cases.

- Few clinical trials reported satisfactory results, however, methodology was not consistent. was lower than that in matched controls by $9 \%$. A recent and larger meta-analysis by Uzzan et al. [15], confirmed these results. The detrimental effect of chronic administration of L-T4 is more pronounced on cortical bone than on trabecular bone in 1996.

During long-term L-T4 replacement therapy, frequent episodes of subclinical hypothyroidism or hyperthyroidism may occur, which may cause cardiovascular abnormalities. Subclinical hyperthyroidism is associated with increased heart rate, left ventricular hypertrophy with concentric remodeling, and impaired ventricular relaxation [16]. Effects of subclinical hypothyroidism is that of impaired systolic and diastolic function and increased intima media thickness $[17,18]$.

Recently, L-T4 has been reported as an oxidative stress generator and an important endogenous factor capable of supporting proliferation of lung cancer cells. Patients with small cell lung carcinoma often present with symptoms of hyperthyroidism (i.e., weight loss and anorexia), an observation that was made many years ago for these patients together with increased serum levels of both T4 and T3 [19].

Monthly follow-up of all pregnant patients is recommended until term and different L-T4 doses can be prescribed according to the baseline TSH level of each. This in fact makes it a great burden for them beside the other burdens of pregnancy [20].

Oral T4 is absorbed at the level of the duodenum, jejunum, and ileum, where some inflammatory disorders may cause hormone malabsorption as celiac disease, small intestine bacterial overgrowth, lactose intolerance, chronic diarrhea due to Crohn's enteritis, and short bowel syndrome [21]. In some gastric disorders as Helicobacter pylori infection and chronic gastritis, a higher dose of oral L-T4 may be needed, highlighting a novel role for the stomach in subsequent intestinal T4 absorption [22]. Chronic obstructive liver disease, pancreatic insufficiency, and cystic fibrosis have also been described to be associated with L-T4 malabsorption [23].

Some frequently used medications cause L-T4 malabsorption as cholestyramine, sucralfate, ferrous sulfate, aluminum, calcium carbonate, carbamazepine, lithium, and amiodarone [24-31]. Soya and dietary rich fiber supplements, including walnuts, papaya and cotton seeds, sequester L-T4 in the gastrointestinal tract $[32,33]$. Furthermore, beverages such as coffee and grapefruit juice and, may cause decreased L-T4 intestinal absorption $[34,35]$.

\section{HISTORY OF ENDOCRINE GLANDS AUTOTRANSPLANTATION}

The implantation of endocrine tissue grafts is likely to become clinically useful for correcting hormonal deficiencies. The principle of autotransplantation of the endocrine glands after subtotal or total excision of the gland, to avoid postoperative functional insufficiency, was proposed by Halsted [36] in 1909. In the following decades, this principle was applied with great success for 
the parathyroid and pancreatic glands, but not for adrenal, testicular or ovarian tissues [37-41]. Data in the literature concerning thyroid autotransplantation are relatively poor and partially controversial. Furthermore, no experimental or clinical studies are documented, which could confirm beyond any doubt the thyroid autograft functional capacity, according to the model of parathyroid autotransplantation. The clinical application of this technique was preceded by several animal studies that proved survival and function of heterotopically implanted thyroid tissue.

\section{ANIMAL EXPERIMENTS}

The earliest documented trial of thyroid autotransplantation was performed in Bulgaria by Chernozemski and Christov [42] in 1967. They published a letter in Nature announcing their pioneer work in autotransplantation and homotransplantation of thyroid tissue in hamster cheek pouch. There was no difficulty with survival of the autotransplants. However, the homotransplants required special treatment with corticosteroids and implantation in special sites as the eye, the brain and testis in order to survive.

In 1968, Nagamine [43] described the technique of microvascular anastomosis for thyroid autotransplantation. And in 1970, Yamane and Kamba [44] described autotransplantation of thyroid tissue in the bone marrow and in the vascular lumen.

Raaf et al. [45] conducted a study in which isogeneic thyroid glands were implanted into thyroidectomized recipient rats in 1975. These grafts, fresh or cultured, were implanted under the renal capsule or in the hamstring muscle. Survival and function of the grafts were evaluated by restoration of normal serum levels of T4, weight gain and histological appearance of re-excised implants. All fresh and cultured isografts showed good function as ectopic thyroid glands, though restoration of normal serum levels of T4 was more rapid with fresh implants. For all the above mentioned experimental studies no details about the technique or the results have been obtained.

The first detailed description of thyroid transplantation was in 1996 in Japan by Shimizu et al. [46], in which both frozen and fresh thyroid tissue autotransplants were used in rats after rendering them hypothyroid by STT. In a group of animals the implanted tissue was placed in the renal subcapsular space, while in another group it was placed in the muscles. Both fresh and frozen thyroid grafts survived. The best recovery of thyroid function was observed after $6-8$ weeks by laboratory studies, histology, immune-histochemical thyroglobulin staining, and isotope scan. The site of implant did not make a difference in the outcome.

Another large study was done by Pasteur et al. [47] in Ukraine in 1999, for developing a new culture technique to achieve the highest activity of newborn pig thyroid tissue hormones and preserve the morphological and other functional characteristics of thyroid follicles. The study showed that during culturing of the thyroid tissue of newborn pig, the morphological and functional features of thyrocytes are preserved for a period of 1 month. The highest functional activity is indicated by conditions of follicular epithelium, interfollicular tissue, colloid and stromal elements in 5th and 10th day organ culture. Results also confirmed the capacity of newborn pig thyrocytes actively produce thyroid hormones in vitro. Therefore, newborn pig thyrocytes culture may be used in experimental transplantology and management of patients with persistent hypothyroidism.

One well-described experimental study was published by Papaziogas et al. [7] in 2002, where TT was done for 38 rabbits with implantation of the fresh thyroid tissue in different muscles of their bodies. Weekly thyroid hormone assessments were done. Progressive reduction in thyroid hormone levels was observed till 2-5 weeks then they gradually increased till a euthyroid state was reached 5-8 weeks after the procedure with corresponding TSH changes. Scintigraphy at 8 weeks showed function in all implantation sites. Histopathological examination of the removed implants 2 days after the scintigram showed functional thyroid follicles in all the examined tissues.

In 2005, Gal et al. [48] provided further details of the technique of thyroid autotransplantation. They did TT for 12 adult mongrel dogs and the autotransplanted thyroid tissue was sliced into 3-4 mm pieces and was frozen at $-196^{\circ} \mathrm{C}$. Later on, the frozen tissue was implanted either in flaps of the greater omentum or in the sternomastoid muscle. Starting levels of serum T3 and $\mathrm{T} 4$ for the animals were between 0.5 and $0.62 \mathrm{mmol} / \mathrm{L}$ and between 10.4 and $14.3 \mathrm{mmol} / \mathrm{L}$, respectively. On the 5 th postoperative day,T3 and T4 levels decreased close to zero for all surviving animals, then gradually increased from the 8th day, and at the 3rd and 4th weeks they finally reached their starting values. Isotope scans of sternocleidomastoid muscle and greater omentum showed a detectable rise in activity, which was significantly different from that of surrounding tissues. Histopathological examination of the sacrificed animals showed viable thyroid tissue.

Another important study was conducted by Dobrinja et al. [49] in Italy in 2008, and involved 60 rats divided into 6 equal groups, where TT was performed for all of them. Fresh and preserved tissue implants were autotransplanted at different time intervals in the rectus abdominis muscle. The rats were followed by weekly FT3, FT4, and TSH for 30 days. Histopathology examinations were done after 1 month. The overall success rate was estimated by the authors to be $70 \%$. They concluded that ectopic thyroid implants are able to survive and function completely if preserved in an adequate medium. Thyroid functions of the implants are recovered more rapidly if transplantation was performed immediately after thyroidectomy than if performed later on.

In a study by Karaman et al. [50] in Turky in 2011, 24 guinea pigs were divided into 4 equal groups. Group A had thyroidectomy incision only made, group B had TT, group C had TT and thyroid autotransplantation, and group D had TT and thyroid heterotransplantation. The pigs were then weekly monitored with measurements of T3, T4, and TSH for 8 weeks. The auto- 
grafts and heterografts were histologically examined at the final stages. In group B, T3/T4 showed a gradual decrease, and increased TSH levels. In groups C and D, T3/T4 showed a gradual decrease, and then a gradual increase until euthyroid levels and the exact opposite was reported for TSH levels. In histological examinations of the grafts, functional thyroid follicles were detected in the grafts of animals of groups $\mathrm{C}$ and D. The study confirmed that a thyroid auto and heterograft could survive and restore its function within 8 weeks afterTT.

\section{HUMAN STUDIES}

Clinical trials of thyroid autotransplantation are not well established yet in the endocrine surgery field. One of the first trials was in 1957 in Italy, for an 18-year-old woman who was admitted to the hospital for excision of her ectopic lingual thyroid and autotransplantation of this thyroid tissue into the right rectus abdominis and the preperitoneal cavity on the left side. No postoperative replacement medication was prescribed and the patient showed signs of hypothyroidism. Gradual recovery of thyroid function was evident clinically 5 months postoperatively. Iodine uptake in the right side of the abdomen only was demonstrated, suggesting that autotransplanted tissues have survived in the muscles [51].

Sheverdin et al. [52] stated that Tsarikovskoji and Tkatsov performed the first immediate autotransplantation of thyroid tissue after STT in 1975, for an adolescent presented with hypothyroidism 6 months postoperatively. However, they proposed the autotransplantation afterTT or STT in children.

In 1984, Pushkar' et al. [53] underwent thyroid autotransplantation for patients who had post-thyroid surgery hypothyroidism. Frozen thyroid tissues were implanted 4-12 months after the initial surgery. A follow-up period of 18 months showed considerable rise in T3 and T4, hypothyroidism disappeared and the patients required no additional replacement therapy. Unfortunately the data about this work was very defective concerning the number of patients, the amount of thyroid tissue resection, the transplanted tissue weight and its implantation site.

Okamoto et al. [54], carried out thyroid autotransplantation after STT for 5 patients presenting with Graves' disease in order to avoid hypothyroidism postoperatively, as the weight of the thyroid remnant was too small ( $3-5 \mathrm{~g}$ ) in 1990. About $0.5-2 \mathrm{~g}$ of thyroid tissue was sliced and autotransplanted into the sternocleidomastoid muscles or the strap muscles. Patients were then followed for 2.2-7.0 years. Postoperatively, serum levels of TSH were normal or slightly elevated in 3 patients, while that of T3 were normal in all the 5 patients. None of the patients fell into a state of overt hypothyroidism. Thyroid scanning with iodine $\left({ }^{123} \mathrm{I}\right)$ or technetium $\left({ }^{99 \mathrm{~m}} \mathrm{Tc}\right)$ revealed active uptake transplantation sites in 4 patients. The authors concluded that autotransplantation may help avoid postoperative hypothyroidism in patients with too small thyroid remnant after STT.

Shimizu et al. [55] reported their first patient who had thyroid autotransplantation of frozen thyroid tissue after TT for Graves' disease in 1991.

In 1992, Sheverdin et al. [52] from Russia followed the results of 246 STT operations for children and adolescents with thyrotoxicosis. Some of these patients had thyroid autotransplantation. Patients were followed for periods that ranged from 2 months to 15 years. Signs of mild hypothyroidism were reported in $3.2 \%$ of the patients with autotransplantation during the 6 months interval postoperatively. In the control group (without autotransplantation) hypothyroidism was reported in $6.6 \%$ of the patients. The author concluded that autotransplantation of part of the excised toxic gland is an effective method to prevent postoperative hypothyroidism. However, again the information available about this study is very defective even it was not clear whether the transplanted tissues were fresh or preserved.

The work of Shimizu et al. [55], in Japan in 2002, though involved 4 patients only, gave more insight about the technique and the results of thyroid autotransplantation. These 4 patients were among a group of Graves' diseases patients who had STT and a part of the excised thyroid was stored frozen at $-196^{\circ} \mathrm{C}$. The 4 patients found replacement therapy impractical and inconvenient and they requested transplantation of their own thyroid tissue after a mean period of 2.8 years. For each patient 2.5-3.5 $\mathrm{g}$ of their own thyrocytes was transplanted in the muscles of the forearm after slicing them into minute pieces. In each case they used 10-12 muscle pockets that were marked with monofilament nylon sutures. Only 1 patient developed recurrence of hypothyroidism and had to resume replacement therapy 6 months after autotransplantation. The authors stated that autotransplantation of cryopreserved thyrocytes is a promising therapeutic technique for management of patients with Graves' disease presenting with permanent postoperative hypothyroidism [56].

In 2003, Roy et al. [57] from India gave further details about the concept of thyroid autotransplantation. They performed modified STT and fresh tissue autotransplantation for $15 \mathrm{pa}-$ tients. These included 7 with Graves' disease, 6 with simple multinodular goiter (MNG) and 2 with nodular toxic goiter. Implantation of thyroid tissue (3-5 g) was performed in the sternocleidomastoid muscle. Clinical follow-up, thyroid hormone profile and ${ }^{99 \mathrm{~m}} \mathrm{Tc}$ scans of the neck were done to assess functions of remnant and transplanted tissues. Six patients with MNG and 4 patients with Graves' disease had functional implants. All patients with MNG who had a functional transplant became euthyroid 6 months postoperatively. Only 1 patient with Graves' disease from the four who had functional transplanted tissue became euthyroid, while the other 3 required postoperative supplemental therapy for hypothyroidism. These findings demonstrated the ability of autotransplanted thyroid tissue to survive, grow and function in muscles away from its native blood supply.

In 2015, Mohsen et al. [58] from Egypt applied the technique 
of fresh thyroid autotransplantation on 40 patients with simple MNG who underwent TT. For 12 patients, $5 \mathrm{~g}$ of their own thyroid tissue were implanted in the thigh muscles using the injection technique, while $10 \mathrm{~g}$ were injected for the other $28 \mathrm{pa}-$ tients. Follow-up was done after 2, 6, and 10 months postoperatively using ${ }^{99 \mathrm{~m}} \mathrm{Tc}$, FT3, FT4, and TSH. The authors reported survival of all transplants with different degree of function. Tengram implants showed better results than 5-g implants and all showed improvement of function with time passage.

In 2016, Saleh [59] from Egypt, performed heterotopic autotransplantation of fresh thyroid tissue for 20 patients who underwentTT (13 with simple MNG, 4 with Graves' disease and 3 with toxic nodular goiter). Intraoperatively, $10-15 \mathrm{~g}$ of the healthiest looking non-nodular part of the excised gland was minced into 1-2 mm slices after stripping of its fibrous capsule. The tissue was then made into an emulsion of $20 \mathrm{~mL}$ lactated Ringer's solution and injected through the rectus femoris muscle in 6-8 different directions using a specially designed wide bore needle. The final postoperative pathology reported a follicular variant of thyroid papillary carcinoma in 2 patients in whom preoperative pathology missed their diagnosis. The 2 patients had their graft excised and were excluded from the study. Follow-up of 18 patients was done to report the survival and function of the heterotopic transplanted thyroid tissue through ${ }^{99 \mathrm{~m}} \mathrm{Tc}$ uptake at 2-month postoperatively and thyroid function tests (FT3, FT4, and TSH) at 2, 4, 6, 8, 10, and 12-month postoperatively. Results confirmed that all implants survived and showed variable degree of function as all the patients had normal ${ }^{99 \mathrm{~m}} \mathrm{Tc}$ uptake at 2-month postoperatively and most of the patients had normal thyroid hormones levels at 12-month postoperatively. The best results in that study were achieved in young patients with preoperative pathology of nodular disease in whom maximum weight of non-nodular healthy thyroid tissue was implanted within a short period of time in the same session of TT.

Clinical application of thyroid autotransplantation was very limited in literature and did not gain popularity, this may be attributed to the small number of candidates for thyroid transplantation, heterogeneity of the transplantation technique, timing of transplantation (where some used frozen thyroid tissue as Shimizu et al. [56], while others used fresh thyroid tissue as Roy et al. [57], and the variable amount of tissue transplanted [52-57].

Future perspectives include applying thyroid autotransplantation on a larger scale, using consistent methodology with the same technique and amount of transplanted tissue. Regular long term follow-up of the patients is also necessary to monitor the fluctuations in thyroid functions and proper response to feedback mechanisms. Moreover, a proper follow-up of the implantation site must be done to detect any change in the nature of the implanted tissue. Whether to apply this technique or not for patients with Graves' disease, is still largely unsettled.

\section{CONCLUSION}

In view of growing understanding of the technique of thyroid heterotopic autotransplantation, it is a safe and easy procedure that provides survival and function of the thyroid graft achieving a postoperative euthyroid state in the majority of selected patients undergoing TT without the need for further administration of L-T4 replacement therapy. Degree of graft function was variable throughout the different studies and affected by different parameters; most important were the preoperative gland pathology and weight of the transplanted tissue. Long-term followup of patients is important especially the TSH level to guard against pituitary hyperfunctioning and also of the implantation site to detect any change in the nature of the implanted tissue with time passage. Further studies on larger populations of patients need to be done to determine the applicability of this process for Graves' disease patients.

\section{CONFLICT OF INTEREST}

No potential conflict of interest relevant to this article was reported.

\section{REFERENCES}

1. Mishra A,Agarwal A,Agarwal G, Mishra SK.Total thyroidectomy for benign thyroid disorders in an endemic region. World J Surg. 2001 Mar;25(3):307-10.

2. Bron LP, O'Brien CJ. Total thyroidectomy for clinically benign disease of the thyroid gland. Br J Surg. 2004 May;91(5):569-74.

3. Arem R, PatschW. Lipoprotein and apolipoprotein levels in subclinical hypothyroidism: effect of levothyroxine therapy. Arch Intern Med. 1990 Oct;150(10):2097-100.

4. Althaus BU, Staub JJ, Ryff-De Leche A, Oberhansli A, Stahelin HB. LDL/HDL-changes in subclinical hypothyroidism: possible risk factors for coronary heart disease. Clin Endocrinol (Oxf). 1988 Feb;28 (2):157-63.

5. Sethi MJ, Parr M, Bhatia V. Management strategies for hypothyroidism in non-compliant patients: a case report and review of literature. S D Med. 2008 Oct;61(10):368-9.

6. Lips DJ, van Reisen MT, Voigt V, Venekamp W. Diagnosis and treatment of levothyroxine pseudomalabsorption. Neth J Med. 2004 Apr; 62(4):114-8.

7. Papaziogas B, Antoniadis A, Lazaridis Ch, Makris J, Kotakidou R, Paraskevas G, et al. Functional capacity of the thyroid autograft: an experimental study. J Surg Res. 2002 Apr;103(2):223-7.

8. Wiersinga WM. Thyroid hormone replacement therapy. Horm Res. 2001;56 Suppl 1:74-81.

9. Dong BJ, Hauck WW, Gambertoglio JG, Gee L, White JR, Bubp JL, et al. Bioequivalence of generic and brand-name levothyroxine products in the treatment of hypothyroidism. JAMA. 1997 Apr;277 (15):1205-13.

10. Bagattoli RM, Vaisman M, Lima JS, Ward LS. Estudo de adesao ao tratamento do hipotiroidismo. Arq Bras Endocrinol Metab. 2000 Dec;44(6):483-7. 
11. Stoffer SS, Szpunar WE. Potency of current levothyroxine preparations evaluated by high-performance liquid chromatography. Henry Ford Hosp Med J. 1988;36(1):64-5.

12. Perros P. European Thyroid Association guidelines on L-t4+L-t3 combination for hypothyroidism: a weary step in the right direction. EurThyroid J. 2012 Jul;1(2):51-4.

13. Langdahl BL, Loft AG, Moller N, Weeke J, Eriksen EF, Mosekilde L, et al. Skeletal responsiveness to thyroid hormone is not altered at menopause. Bone. 1996 Nov;19(5):557-64.

14. Faber J, Galloe AM. Changes in bone mass during prolonged subclinical hyperthyroidism due to L-thyroxine treatment: a meta-analysis. Eur J Endocrinol. 1994 Apr;130(4):350-6.

15. Uzzan B, Campos J, Cucherat M, Nony P, Boissel JP, Perret GY. Effects on bone mass of long term treatment with thyroid hormones: a meta-analysis. J Clin Endocrinol Metab. 1996 Dec;81(12):4278-89.

16. Fatourechi V. Adverse effects of subclinical hyperthyroidism. Lancet. 2001 Sep;358(9285):856-7.

17. Biondi B, Fazio S, Palmieri EA, Carella C, Panza N, Cittadini A, et al. Left ventricular diastolic dysfunction in patients with subclinical hypothyroidism. J Clin Endocrinol Metab. 1999 Jun;84(6):2064-7.

18. Monzani F, Caraccio N, Kozakowa M, Dardano A, Vittone F, Virdis A, et al. Effect of levothyroxine replacement on lipid profile and intima-media thickness in subclinical hypothyroidism: a double-blind, placebo- controlled study. J Clin Endocrinol Metab. 2004 May;89 (5):2099-106.

19. Meng R, Tang HY, Westfall J, London D, Cao JH, Mousa SA, et al. Crosstalk between integrin $\alpha v \beta 3$ and estrogen receptor- $\alpha$ is involved in thyroid hormone-induced proliferation in human lung carcinoma cells. PLoS One. 2011 Nov;6(11):e27547.

20. Yu X, Chen Y, Shan Z, Teng W, Li C, ZhouW, et al. The pattern of thyroid function of subclinical hypothyroid women with levothyroxine treatment during pregnancy. Endocrine. 2013 Dec;44(3):710-5.

21. Centanni M. Thyroxine treatment: absorption, malabsorption, and novel therapeutic approaches. Endocrine. 2013 Feb;43(1):8-9.

22. Centanni M, Gargano L, Canettieri G, Viceconti N, Franchi A, Delle Fave G, et al. Thyroxine in goiter, Helicobacter pylori infection, and chronic gastritis. N Engl J Med. 2006 Apr;354(17):1787-95.

23. Hays MT. Thyroid hormone and the gut. Endocr Res. 1988;14(23):203-24.

24. Northcutt RC, Stiel JN, Hollifield JW, Stant EG Jr. The influence of cholestyramine on thyroxine absorption. JAMA. 1969 Jun;208(10): 1857-61.

25. Havrankova J, Lahaie R. Levothyroxine binding by sucralfate. Ann Intern Med. 1992 Sep;117(5):445-6.

26. Shakir KM, Chute JP,Aprill BS, Lazarus AA. Ferrous sulfate-induced increase in requirement for thyroxine in a patient with primary hypothyroidism. South Med J. 1997 Jun;90(6):637-9.

27. Liel Y, Sperber AD, Shany S. Nonspecific intestinal adsorption of levothyroxine by aluminum hydroxide. Am J Med. 1994 Oct;97(4): 363-5.

28. Schneyer CR. Calcium carbonate and reduction of levothyroxine efficacy. JAMA. 1998 Mar;279(10):750.

29. Singh N, Singh PN, Hershman JM. Effect of calcium carbonate on the absorption of levothyroxine. JAMA. 2000 Jun;283(21):2822-5.

30. De Luca F, Arrigo T, Pandullo E, Siracusano MF, Benvenga S, Trimarchi F. Changes in thyroid function tests induced by 2 month carbamazepine treatment in L-thyroxine-substituted hypothyroid children. Eur J Pediatr. 1986 Apr;145(1-2):77-9.

31. Singh N, Hershman JM. Interference with the absorption of levothyroxine. Curr Opin Endocrinol Diabetes. 2003 Oct;10(5):347-52.

32. Bell DS, Ovalle F. Use of soy protein supplement and resultant need for increased dose of levothyroxine. Endocr Pract. 2001 May-Jun;7 (3):193-4.

33. Deiana L, Marini S, Mariotti S. Ingestion of large amounts of papaya fruit and impaired effectiveness of levothyroxine therapy. Endocr Pract. 2012 Jan-Feb;18(1):98-100.

34. Lilja JJ, Laitinen K, Neuvonen PJ. Effects of grapefruit juice on the absorption of levothyroxine. Br J Clin Pharmacol. 2005 Sep;60(3): 337-41.

35. Benvenga S, Bartolone L, Pappalardo MA, Russo A, Lapa D, Giorgianni G, et al. Altered intestinal absorption of L-thyroxine caused by coffee. Thyroid. 2008 Mar;18(3):293-301.

36. Halsted WS. Auto- and isotransplantation, in dogs, of the parathyroid glandules. J Exp Med. 1909 Jan;11(1):175-99.

37. Walker RP, Paloyan E, KelleyTF, Gopalsami C, Jarosz H. Parathyroid autotransplantation in patients undergoing a total thyroidectomy: a review of 261 patients. Otolaryngol Head Neck Surg. 1994 Sep;111 (3 Pt 1):258-64.

38. Rabkin JM, Olyaei AJ, Orloff SL, Geisler SM, Wahoff DC, Hering BJ, et al. Distant processing of pancreas islets for autotransplantation following total pancreatectomy. Am J Surg. 1999 May;177(5):423-7.

39. Nabishah BM, Khalid BA, Morat PB, Zanariyah A. Regeneration of adrenal cortical tissue after adrenal autotransplantation. Exp Clin Endocrinol Diabetes. 1998;106(5):419-24.

40. Barten EJ, Newling DW. Transplantation of the testis; from the past to the present. Int J Androl. 1996 Aug;19(4):205-11.

41. Callejo J, Jauregui MT, Valls C, Fernandez ME, Cabre S, Lailla JM. Heterotopic ovarian transplantation without vascular pedicle in syngeneic Lewis rats: six-month control of estradiol and folliclestimulating hormone concentrations after intraperitoneal and subcutaneous implants. Fertil Steril. 1999 Sep;72(3):513-7.

42. Chernozemski I, Christov K. Autotransplantation and homotransplantation of thyroid gland in the hamster cheek pouch. Nature. 1967 Jul;215(5096):70.

43. Nagamine S. Experimental studies on the autotransplantation of thyroid gland using micro-vascular anastomoses. Nihon Geka Hokan. 1968 Jan;37(1):32-57.

44. Yamane I, Kamba S. Autotransplantation of the thyroid in the bone marrow and the vascular lumen. Yonago Acta Med. 1970 Dec;14(3): 131-45.

45. Raaf JH,Van Pilsum JF, Good RA. Fresh and cultured thyroid gland: survival and function after implantation. Ann Surg. 1976 Feb;183(2): 146-56.

46. Shimizu K, Nagahama M, Kitamura Y, Igarashi T, Aida N, Tanaka S. Improvement of thyroid function after autotransplantation of cryopreserved thyroid tissues in rats: clinical application of the procedure to patients with persistent hypothyroid Graves' disease after thyroidectomy. Thyroidol Clin Exp. 1996;8:55-62.

47. Pasteur IP, Tronko ND, Drozdovich II, Turchin IS, Balla IA. Thyroid transplantation: possibility of application for the treatment of persistent hypothyroidism and study of mechanisms of interaction between graft and hypothalamic-pituitary axis of recipient. In: Kitagawa Y, Matsuda T, Iijima S, editors. Animal cell technology: basic \& applied aspects. vol. 10. Dordrecht, Netherlands: Kluwer Academic Publishers; 1999. p. 289-93.

48. Gal I, Miko I, Furka I, Nagy D. Autotransplantation of cryopreserved thyroid tissue in dogs. Magy Seb. 2005 Apr;58(2):93-9.

49. Dobrinja C, Trevisan R, Trevisan G, Liguori G. Autotransplantation of thyroid tissue in rats: an experimental study. Ann Ital Chir. 2008 Sep-Oct;79(5):389-95.

50. Karaman M,Tuncel A, Sheidaei S, Karabulut MH,Tatlipinar A. Functional capacity of the thyroid autograft and heterograft: an experimental study. Head Neck. 2012 May;34(5):702-8.

51. Minuto FM, Fazzuoli L, Rollandi GA, Derchi LE, Biassoni P. Successful autotransplantation of lingual thyroid: 37-year follow-up. Lancet. 1995 Sep;346(8979):910.

52. Sheverdin IuP.The results of a 15-year observation of patients with an autotransplant of thyroid gland fragments performed to prevent 
postoperative hypothyroidism. Vestn Khir Im I I Grek. 1992 Feb;148 (2):152-6.

53. Pushkar' NS, Makedonskaia VA, Utevskii AM, ChuikoVA, Karpenko LG. Autoimplantation of cryopreserved (-196 degrees C) thyroid gland parenchyma as a treatment method in postoperative hypothyroidism. Probl Endokrinol (Mosk). 1984 Sep-Oct;30(5):42-6.

54. Okamoto T, Fujimoto Y, Obara T, Ito Y, Kodama T, Kusakabe K. Trial of thyroid autotransplantation in patients with Graves' disease whose remnant thyroid has unintentionally been made too small at subtotal thyroidectomy. Endocrinol Jpn. 1990 Feb;37(1):95-101.

55. Shimizu K, Kitamura Y, Nagahama M, Shoji T. A fundamental study of the thyroid transplantation for the patient with irreversible hypothyroidism (the first report: an autotransplantation of cryopreserved thyroid): preliminary report. Nihon Geka Gakkai Zasshi. 1991 Dec;
92(12):1728.

56. Shimizu K, Kumita S, Kitamura Y, Nagahama M, Kitagawa W, Akasu $\mathrm{H}$, et al. Trial of autotransplantation of cryopreserved thyroid tissue for postoperative hypothyroidism in patients with Graves' disease. J Am Coll Surg. 2002 Jan;194(1):14-22.

57. Roy PG, Saund MS, Thusoo TK, Roy D, Sankar R. Fate of human thyroid tissue autotransplants. Surg Today. 2003;33(8):571-6.

58. Mohsen AA, Nada AA, Ibrahim MY, Ghaleb AH, Abou-Gabal MA, Mohsen AA, et al.Technique and outcome of autotransplanting thyroid tissue after total thyroidectomy for simple multinodular goiters. Asian J Surg. 2017 Jan;40(1):17-22.

59. Saleh AM. Survival and functional capacity of heterotopic thyroid autograft after total thyroidectomy for benign goiters [dissertation]. Alexandria, Egypt: Faculty of Medicine,Alexandria University; 2016. 